\title{
Red cell size as measured by the Coulter model $\mathbf{S}$
}

\author{
TAKASHI OKUNO
}

From the Department of Haematology, Lutheran General Hospital, Park Ridge, Illinois

SYNOPSIS The MCV (mean corpuscular volume) was examined by the Coulter model S. It was found that the MCV measured by the Coulter $S$ was larger than the generally accepted range 82 to 92 , or 76 to $96 \mu^{3}$. The range in 500 healthy individuals was 82.2 to $100.6 \mu^{3}$. It was also found that the mean MCV became larger with increasing age. No sex difference was found. The low MCV by manual methods was generally thought to be attributed to less accurate measurement of erythrocyte counts.

The mean corpuscular volume (MCV) has been widely used for evaluations of haematological disorders. Since the MCV has been calculated from erythrocyte counts and haematocrit, its accuracy has been largely dependent on these two, especially erythrocyte counts, determinations. Because of inaccurate erythrocyte counts by the manual method, which has a large inherent error, the MCV has traditionally been regarded as giving unacceptably inaccurate values in clinical medicine (Black, 1971). The recent advent of electronic counters, however, has enabled us to measure directly the MCV (Brittin, Brecher, and Johnson, 1969), (Pinkerton, Spence, Ogilvie, Ronald, Marchant, and Ray, 1970).

A range of 82 to $92 \mu^{3}$ has been generally accepted as the normal values for the MCV, but these have been obtained by the manual methods of erythrocyte counting and haematocrit. This range has been found to be somewhat low when an electronic device was used for erythrocyte counts (Fairbanks, Fahey, and Bentler, 1971) or when the Coulter S was used (Silver and Frankel, 1971). In this study, 500 healthy individuals were examined for haematological values measured by the Coulter $\mathbf{S} .^{1}$

\section{Materials and Methods}

Haematological examinations were performed from May to July 1971, using the Coulter model S. Sources of blood were 202 blood donors to the Lutheran General Hospital blood bank and 298 hospital employees who were examined at regular physical examinations and were found to be healthy.

${ }^{1}$ Coulter Electronics, Hialeah, Fla, USA. Coulter Electronics Ltd, Dunstable, Beds

Received for publication 6 April 1972
Five hundred individuals were divided into groups according to sex and age. Each group consisted of 50 individuals. The average age of the population was 35.3 years for males and 35.5 years for females. The age range was 16 to 68 years for males, and 16 to 69 years for females.

During the period of study, the Coulter $\mathbf{S}$ was regularly checked for reliability according to the manufacturer's instruction. Regular quality controls of the Coulter $S$ were as follows:

Five blood samples kept in refrigerator from the previous day were checked every day by the Coulter model S, and the results of the day and the day before were compared. Three times a week, the standard sample provided by the Coulter Company was examined by both Coulter $\mathbf{S}$ and manual methods. The manual methods included the Coulter model $\mathrm{F}$ for erythrocyte counts, the cyanmethohaemoglobin method using Drabkin's solution for haemoglobin, and a microhaematrocrit method by centrifuging for five minutes at $12000 \mathrm{rpm}$ for haematocrit values.

\section{Results}

The mean MCV of a population of 500 healthy individuals was 91.4 for males and 91.3 for females (Table I). The older age groups had progressively enlarging MCV values: thus the difference of the means for the 16-19 age group and the group aged

\begin{tabular}{llll}
\hline & $M C V\left(\mu^{3}\right)$ & $M C H(\mu \mu g)$ & $M C H C(\%)$ \\
\hline Male & $91.4 \pm 9 \cdot 2$ & $30 \cdot 7 \pm 3 \cdot 3$ & $33.6 \pm 2.3$ \\
Female & $91.3 \pm 9.4$ & $30.5 \pm 3 \cdot 3$ & $33.5 \pm 1.9$ \\
\hline
\end{tabular}

Table I Means and 2 standard deviations of blood indices at all ages based on 500 healthy individuals 
Fig. 1 The $M C V$ in different age groups of 250 male subjects. Solid lines indicate the mean MCV of the group

50 and above was 3.5 for both males and females (Fig. 1). The difference of the means was analysed statistically (Table II). The difference between the 16-19 group and that of 50 and above, for example, was statistically significant with a $t$ value of 3.660 $(\mathrm{P}<0.001)$. A similar observation was made for the female population $(P<0.001)$. Sex had no effect on the mean corpuscular volume. The greatest difference in the MCV between male and female was found in the age group 40-49, where the difference of the means was 0.96 (t 1.048, $\mathrm{P}>0.25$ ).

\begin{tabular}{|c|c|c|c|c|}
\hline Age Group & $16-19$ & & & \\
\hline $20-29$ & $\begin{array}{l}\text { d } 0.80 \\
\text { t } 0.954 \\
P>0.4\end{array}$ & $20-29$ & & \\
\hline $30-39$ & $\begin{array}{l}\text { d } 1.60 \\
\text { t } 1.518 \\
\text { P }>0.1\end{array}$ & $\begin{array}{l}\text { d } 0.80 \\
\text { t } 0.714 \\
P>0.4\end{array}$ & & \\
\hline $40-49$ & $\begin{array}{l}\text { d } 1.92 \\
\text { t } 2.323 \\
P>0.02\end{array}$ & $\begin{array}{l}\text { d } 1 \cdot 12 \\
\text { t } 1 \cdot 258 \\
P>0 \cdot 2\end{array}$ & $\begin{array}{l}30-39 \\
\text { d } 0.34 \\
\text { t } 0.314 \\
P>0.8\end{array}$ & \\
\hline $\begin{array}{l}50 \text { and } \\
\text { above }\end{array}$ & $\begin{array}{l}\text { d } 3.40 \\
\text { t } 3.67 \\
\text { P }<0.001\end{array}$ & $\begin{array}{l}\text { d } 2.60 \\
\text { t } 2.953 \\
\text { P }<0.001\end{array}$ & $\begin{array}{l}\text { d } 1.80 \\
\text { t } 1.702 \\
\text { P }>0.5\end{array}$ & $\begin{array}{l}\text { d } 1.50 \\
\text { t } 1.712 \\
\text { P }>0.05\end{array}$ \\
\hline
\end{tabular}

Table II Difference of the $M C V$ in different age groups each of 50 healthy females

To determine the effect of selection of population on the MCV, blood donor and non-donor populations were compared. The average MCV of the male blood donor was 91.8 and that of the non-blood

donor was $90 \cdot 7$. No statistical difference was seen (P > 0.05). Similarly, no difference was seen between 으. the blood donor and non-blood donor of the female population $(\mathrm{P}>0.30)$.

The results of manual and the Coulter $\mathrm{S}$ methods were compared (Table III). One hundred and eight samples were checked by both methods during the period of this study. No statistical significance was observed in the difference of the two procedures for कै haematocrit and MCV values.

\begin{tabular}{llllll}
\hline & $\begin{array}{l}\text { Difference } \\
\text { of Means }\end{array}$ & $\begin{array}{l}\text { Coefficient Student's } \\
\text { of } \\
\text { Correlation } \\
\text { t Test }\end{array}$ & $\begin{array}{l}\text { Degrees of P Preedom } \\
\text { Freed }\end{array}$ \\
\hline $\begin{array}{c}\text { RBCs } \\
\left(\times 10^{6}\right)\end{array}$ & 0.04 & 0.799 & 13.50 & 105 & $<0.001$ \\
$\begin{array}{c}\text { Haematocrit } \\
(\%)\end{array}$ & 0.153 & 0.991 & 72.93 & 105 & $<0.001$ \\
\begin{tabular}{c} 
MCV $\left(\mu^{3}\right)$ \\
\hline
\end{tabular} & 1.02 & 0.656 & 8.82 & 105 & $<0.001$ \\
\hline
\end{tabular}

Table III Comparison of the manual methods and the Coulter $S$ for the erythrocyte count, haematocrit, and mean corpuscular volume based on 108 determinations

Figure 2 shows the relations between different age groups and the values for the MCV, haematocrit, erythrocytes, and haemoglobin. The red blood count became progressively lower with increasing age. The difference in the red blood count was statistically significant between certain age groups. The difference between the 16-to-19 age group and the 40-to-49 age group of males, for example, was $31.98 \times 10^{6}(\mathrm{t} \mathrm{4.3611,} \mathrm{P}>0.001)$.

\section{Discussion}

Since its introduction, the Coulter $\mathbf{S}$ has been used widely in laboratories for haematological examinations. Its accuracy, precision, and reproducibility 음 have been studied in detail (Brittin et al, 1969; Pinkerton et al, 1970; Sharp and Ballard, 1970). Because of its accurate measurement of the MCV, N attention has now been directed to the changes in the MCV in various diseases. In iron-deficiency 0 anaemia, for example, the MCV was found to fall $\tilde{\omega}$ fairly early and is an excellent parameter for assessing 0 the disease and the response to therapy (Black, 1971). The MCHC, on the other hand, has become less $\Phi$ useful clinically since the advent of electronic auto-? matic counters (England, Walford, and Waters, $\underset{T}{T}$ 1971). There are few reports of normal values measured by the Coulter S. By studying 500 healthy individuals, it was found that the MCV by the $\stackrel{\mathbb{Q}}{\varrho}$ Coulter $S$ was larger than the generally accepted one (Table I). 


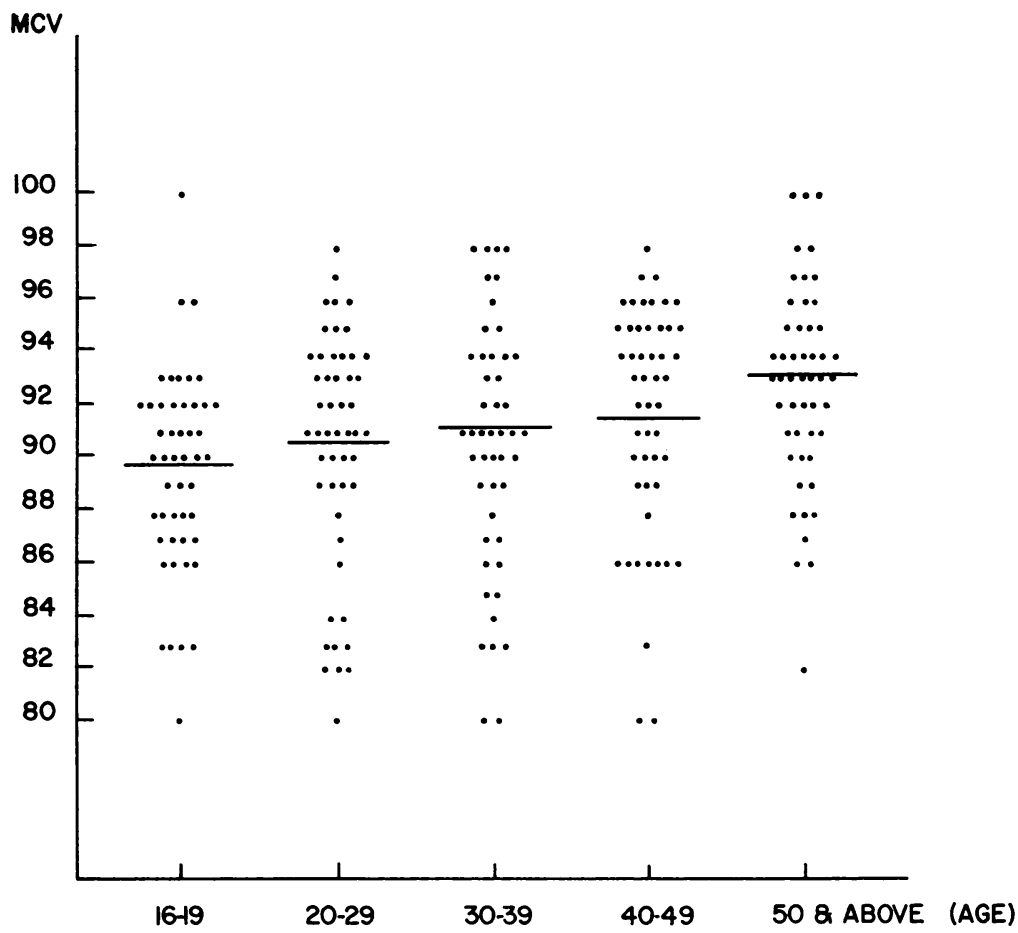

Fig. 2 Changes in different age groups of male population of the mean corpuscular volume $(M C V)$, erythrocyte count $(R B C)$, haemoglobin $(H b)$, and haematocrit $(H C T)$. No statistical differences in $\mathrm{Hb}$ and $\mathrm{HCT}$ between different age groups were observed. The MCV and RBC showed statistically significant differences between younger and older age groups. The values for the 20-29 age group were taken as $100 \%$

Values of 82 to $92 \mu^{3}$ have long been regarded as the accepted normal MCV (Davidsohn and Wells, 1962; Wintrobe, 1967), and have been obtained from erythrocyte counts by the haemocytometer and haematocrit values by the macro-or microhaematocrit procedures. As more precise methods for erythrocyte counts became available, the values of the MCV were challenged (Fairbanks et al, 1971; Silver and Frankel, 1971). They are too low to be applied to clinical haematology studies for macrocytosis. The large MCV obtained by electronic devices was further confirmed by measuring by the Coulter S. Silver and Frankel, using the Coulter $S$ for the MCV values, found that 83.6 to $99.2 \mu^{3}$ were the normal values in 200 subjects tested. Their study was based on 100 blood donors and 100 student nurses. The population they studied, however, did not reflect a cross section of the general population, whereas in this study 500 healthy individuals accurately represented age and sex of the sample. The small MCV by manual methods was generally considered to be due to less accurate erythrocyte counts and was not attributable to automation of the analysis (Silver and Frankel, 1971). This was supported by the comparison of the semi-automated methods and the Coulter $S$ in this study (Table III).
Some care should be taken in using the values obtained by the Coulter S. As Brittin has observed, the red cells as they pass through the aperture of the electronic counting devices may become distorted to some extent (Bull, 1968), but distortion, can be eliminated when the aperture of the Coulter $S$ used is $70 \times 98 \mu$ long or longer. The aperture used in this study was $70 \times 100 \mu$ long. Spurious macrocytes can result from cold agglutinin when the Coulter $\mathbf{S}$ is used (Hattersley, Gerard, Caggiano, and Nash, 1971; Petrucci, Dunne, and Chapman, 1971). Since the haematocrit was calculated from the MCV and erythrocyte count in the Coulter $\mathrm{S}$, the haematocrit became disproportionally lower in such cases, and the MCHC, calculated by dividing haemoglobin by haematocrit, higher. The MCHC for this reason should be used as a quality control measure and any MCHC values more than $36 \%$ should be carefully evaluated. In this study, only two samples showed an MCHC of more than $36 \%$. None of the two showed microagglutination by microscopic examinations. Another source of possible error in determinations by the Coulter $\mathbf{S}$ is that abnormally fragile cells may be destroyed as a result of increased mechanical trauma as the cells go through the tubing or of chemical injuries by diluent solutions. As pointed 
out by Luke, Koepke, and Siegel (1971), abnormally low leucocyte counts in patients on immunosuppressive drugs or in uraemia may be due to abnormally fragile laucocytes. Although this possibility cannot be excluded as a cause of the high MCV by the Coulter $\mathrm{S}$, the comparison of the manual and Coulter $\mathbf{S}$ methods (Table III) did not indicate mechanical or chemical injuries to the erythrocytes by the Coulter $\mathrm{S}$.

In this study, the difference in the MCV between the young and old age groups, regardless of sex, was prominent and was statistically significant (Table II). This has been reported elsewhere (Okuno, 1971). The physiological effects of aging on haematopoietic functions are difficult to evaluate (Thomas and Powell, 1971). Many papers in the literature deal with a decline of haemoglobin or erythrocyte counts in older age groups (Hawkins, Speck, and Leonard, 1954; Myers, Saunders, and Chalmers, 1968). The decline in haemoglobin is thought to be of a nutritional rather than a physiological character (Thomas and Powell, 1971). In most textbooks, however, there are no descriptions of changes in the $\mathrm{MCV}$ in old age. Although the reasons for a large MCV are not known in the older age group in this study, there appeared to be some relationship between hypoxia and the size of red cells. A large MCV can be seen in individuals who are chronically exposed to lower oxygenation levels (Hurtado, Merino, and Delgado, 1945). Lambert and Morris also observed that individuals who were chronically exposed to carbon monoxide showed a high MCV (Lambert and Morris, 1971). They have also seen an increase in the MCV among smokers. It is quite conceivable that more individuals in the older age group than in young age group have suffered from chronic hypoxia because of chronic lung diseases, though clinically asymptomatic, or directly because of chronic smoking. No difference in the MCV because of sex, however, co $t$ ld be explained on the basis of smoking effects on the MCV because it has been generally thought that there are more smokers in male than in female groups (Graham, Levin, and Lilienfeld, 1960).

I should like to thank Mr P. Richman for the illustrations and Miss M. Baalson for typing the manuscript.

\section{References}

Black, P. J. (1971). Epitaph for the MCHC. Brit. med. J., 4, 492-493.

Brittin, G. M., Brecher, G., and Johnson, C. A. (1969). Evaluation of the Coulter counter model S. Amer. J. clin. Path., 52, 679-694.

Bull, B. S. (1968). On the distribution of red cell volumes. Blood, 31 , 503-515.

Davidsohn, I., and Wells, B. B. (1952). Todd-Sanford Clinical Diagnosis by Laboratory Methods, 13th ed., p. 948. Saunders, Philadelphia.

England, J. M., Walford, D. M., and Waters, D. A. W. (1971). Epitaph for the MCHC. Brit. med. J., 4, 232-233.

Fairbanks, V. F., Fahey, J. L., Bentler, E. (1971). Clinical Disorders of Iron Metabolism, 2nd ed., p. 178. Grune and Stratton, New York and London.

Graham, S., Levin, M., and Lilienfeld, A. (1960). The socioeconomic distribution of cancer of various sites in Buffalo, N.Y., 1948 1952. Cancer (Philad.), 13, 180-191.

Hattersley, P. G., Gerard, P. W., Caggiano, V., and Nash, D. R. (1971). Erroneous values on the model $S$ Coulter counter due to high titer cold autoagglutinins. Amer. J. clin. Path., 55, 442-446.

Hawkins, W. W., Speck, E., and Leonard, V. G. (1954). Variation of the haemoglobin level with age and sex. Blood, 9, 999-1007.

Hurtado, A., Merino, C., and Delgado, E. (1945). Influence of anoxemia on the hemopoietic activity. Arch. intern. Med., 75, 284-323.

Lambert, R. J. W., and Morris, J. E. W. (1971). Red cell size and air composition. Brit. med. J., 3, 706.

Luke, P. G., Koepke, J. A., and Siegel, R. R. (1971). The effects of immunosuppressive drugs and uremia on automated leukocyte counts. Amer. J. clin. Path., 56, 503-507.

Myers, A. M. Saunders, C. R. G., and Chalmers, D. G. (1968). The haemoglobin level of fit elderly people. Lancet, 2, 261-263.

Okuno, T. (1972). Red cell size and age. Brit. med.J., in press.

Petrucci, J. V., Dunne, P. A., and Chapman, C. C. (1971). Spurious erythrocyte indices as measured by the model $\mathrm{S}$ Coulter counter due to cold agglutinins. Amer. J. clin. Path., 56, 500-502.

Pinkerton, P. H., Spence, I., Ogilvie, J. C., Ronald, W. A., Marchant, P., and Ray, P. K. (1970). An assessment of the Coulter counter model S. J. clin. Path., 23, 68-76.

Sharp, A. A., and Ballard, B. C. D. (1970). An evaluation of the Coulter S counter. J. clin. Path., 23, 327-335.

Silver, H., and Frankel, S. (1971). Normal values for mean corpuscula volume as determined by the model $\mathrm{S}$ Coulter counter. Amer. J. clin. Path., 55, 438-441.

Thomas, J. H., and Powell, D. E. B. (1971). Blcod Disorders in the Elderly. Wright, Bristol.

Wintrobe, M. M. (1967). Clinical Hematology, 6th ed., p. 86. Lea and Febiger, Philadelphia. 